\title{
Preauricular Swelling Mimicking a Tumour: Dissolution of Mandibular Capitulum Following Trauma in a 15-Year Old Child
}

\author{
REINHARD E. FRIEDRICH and FELIX K. KOHLRUSCH \\ Department of Oral and Cranio-Maxillofacial Surgery, Eppendorf University Hospital, \\ University of Hamburg, Hamburg, Germany
}

\begin{abstract}
Aim: The report is about diagnosis, therapy, and follow-up of a 15-year old boy, who experienced facial swelling and impaired mouth opening after a sport accident. Case Report: Diagnosis of mandibular damage was delayed due to inadequate clinical investigation and radiography after trauma and only became clear after a parotid swelling occurred sometime later resulting from the dissolution of the upper part of the articular process. Follow-up control over a period of three years showed a partial restoration of the articular process but some inhibition of mouth opening combined with slight deviation of the mandible to the affected side remained over the years. Conclusion: This report reminds us that parotid swelling can be the result of mandibular trauma without a recent history of physical injury to this region. Therefore, the basic standards of radiologic diagnosis should be maintained and the limited restoring capacity of the condylar process in adolescence should be acknowledged.
\end{abstract}

In patients with acute mandibular trauma it is often necessary to identify or exclude a fractured bone (1). Therefore, the application of standardized X-rays to the region of interest is an indispensable diagnostic routine (2). In particular the diagnosis of trauma to the mandibular condyle is regularly dependent on adequate imaging (2). Failure to adequately recognize and treat mandibular fractures can lead to complications such as osteomyelitis, ankylosis, pseudarthrosis

This article is freely accessible online.

Correspondence to: Reinhard E. Friedrich, MD, DMD, Ph.D., Department of Oral and Cranio-Maxillofacial Surgery, Eppendorf University Hospital, University of Hamburg, Martinist. 52, D-20246 Hamburg, Germany. Tel: +49 40741053259, e-mail: rfriedrich@uke.de

Key Words: Mandible, condyle, capitulum, fracture, anatomy, vascularization, necrosis. and dissolution of the bone. However, the majority of injuries to the mandibular condyle do not cause a fracture. Trauma to the mandibular condyle may be restricted to distortions of the capsule and internal derangement of the ligaments. These injuries can only be assumed on conventional, i.e. plain X-rays (3). Trauma to capsule and disc of the joint may feature distinct findings on sectional images of the temporomandibular joint (TMJ), such as magnetic resonance imaging (MRI) or computed tomography (CT) (2). Indeed, even displacement of the temporomandibular disc as the sole recognizable trauma consequence can cause absorption of condylar bone in individual cases (4). However, most mandibular fractures of the condylar bone are adequately represented on conventional radiographs, if established diagnostic standards are maintained $(5,6)$. The mandibular fractures may require different techniques to restore bone continuity and shape (1, 6-9).

Following recent developments in maxillofacial surgery, open reduction and internal fixation (ORIF) are advocated as the gold standard of mandibular condyle fracture treatment (10). Many authors share the preference for the surgical treatment of articular fractures, but there are controversies as to the indication for osteosynthesis of non-dislocated fractures and some types of stable reduced fragments that may allow healing without osteosynthesis (10-13). Osteosynthesis in the treatment of condylar fractures in children is still a matter of debate (13-20). There is general agreement that it is mandatory to secure reduced mobility to the condylar region for a certain period of time (19) if the option of conservative fracture treatment has been chosen (20). This measure has to be followed by early functional loading of the bone and utilization of the joint to prevent arthrosis (20). However, in cases with ORIF very early articular mobilisation is advocated $(10,12)$.

In some cases, neither medical history nor conventional radiographs may appropriately reveal a fracture. In particular, non-dislocated fractures can pose diagnostic problems (7). Diagnosis may be impossible in cases with imaging restricted to one radiographic plain (3). Furthermore, injuries to vessels 

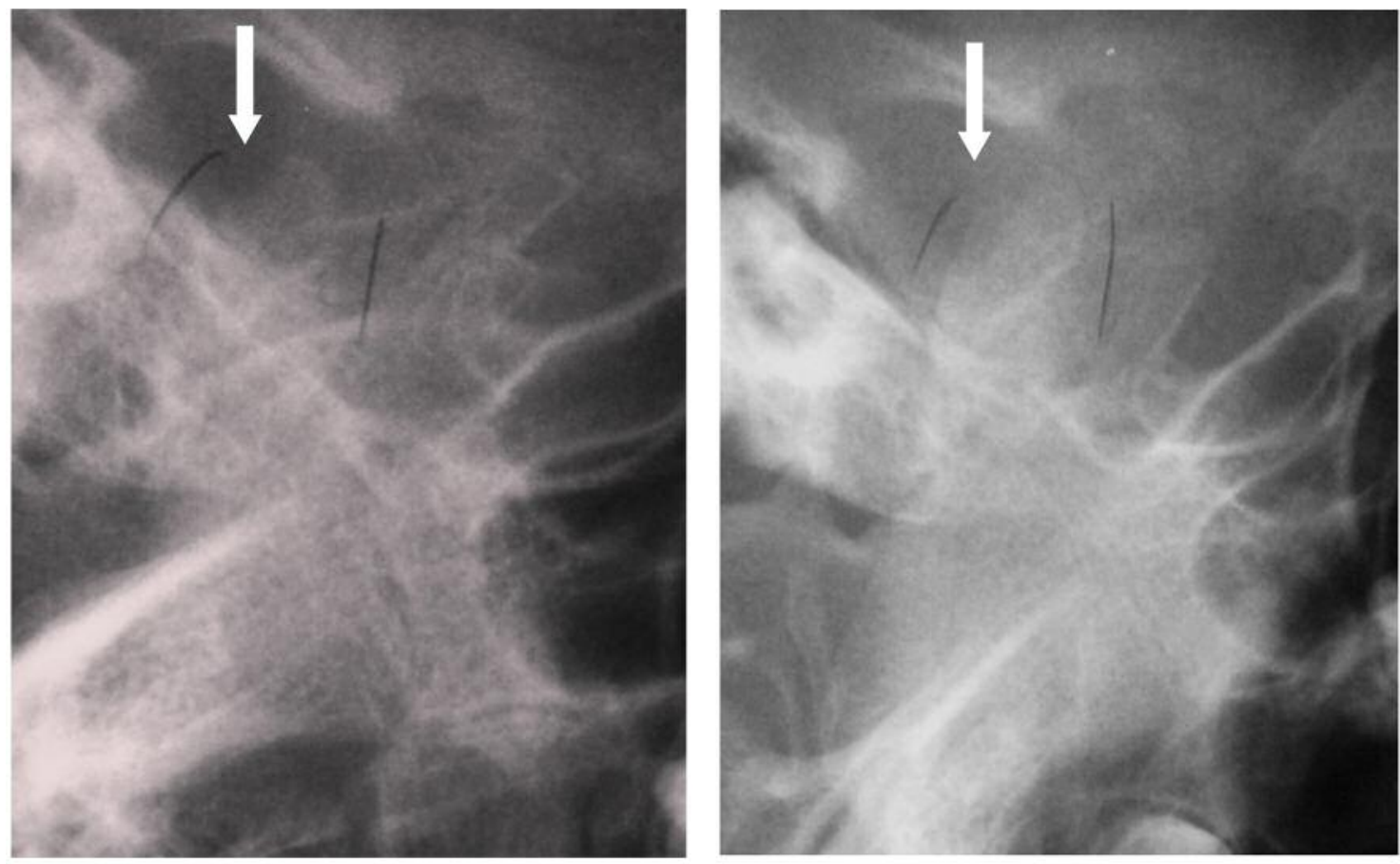

Figure 1. Radiographic representation of the right TMJ with the mouth closed (left) and open (right). With the mouth closed, the condyle is slightly in front of the glenoid fossa and already on the articular eminence. When the mouth is open, the condyle is slightly more anterior. In both figures, the posterior margin of the mandible is visible as a continuous line. The capitulum appears to be somewhat kinked when the mouth is closed. In contrast, this kink between capitulum and caudal parts of the condyle is no longer traceable on the radiograph with the mouth open. The upper dorsal, that is to say articulating, surface of the bone is no longer completely defined in both images (Arrows in both images). The handwritten markings anterior and distal to the condyle come from the original inscription on the exposed radiography.

that are relevant for maintenance of condylar nutrition can lead to condyle necrosis, without apparent fracture visible on radiographs (21). It is not clear how to treat a patient with acute condylar trauma but no evidence of fracture, except advice to avoid maximum mouth opening or the eventual application of temporary immobilisation of the TMJ.

The aim of this report was to describe the consequence of delayed diagnosis of acute condylar trauma in an adolescent, to re-emphasize the principles of adequate mandibular trauma diagnostics and the need for follow-up control of maxillofacial trauma patients.

\section{Case Report}

The 15-year old boy was admitted to the oral and maxillofacial surgery outpatient clinic for diagnosis and therapy of a swelling of the right cheek. Six weeks ago the patient was kicked with a foot into his face during a football game. He neither vomited nor fell unconscious after this collision with another football player. The affected facial skin remained intact during the physical attack. However, he experienced an immediate swelling of the affected side of the face. This swelling of the right cheek region reduced within a few days but then an ipsilateral pre-auricular swelling became apparent about one week after trauma. This swelling persisted and prompted the parents to seek for medical advice. Two weeks following the trauma, the patient was investigated by an outpatient practitioner who performed an X-ray of the affected jaw region (Figure 1). The radiograph was judged to show no signs of a fracture in the right condylar region. The patient was advised to protect the joint by omitting extensive articular movements and initially discharged. However, the swelling did not reduce in size and the patient noticed an unspecified alteration of dental occlusion over time. Therefore, the patient returned to the practitioner about 4 weeks after trauma.

Now a magnetic resonance imaging of the region was ordered to disclose possible space occupying lesions of the parotid region, in particular a neoplasm. On MRI, a large, spindle-shaped, fluid-filled lesion was depicted that was located predominantly in the dorsal part of the masseter muscle and to a lesser part in the region of the upper part of the ramus (Figure 2). Parts of the masseter muscle adjacent to the space-occupying lesion were thickened and showed intensified signaling. The muscle's fascia was slightly prominent to the lateral side due to tumour extension. The dorsal part of the tumour spread into the anterior parotid. Also, 

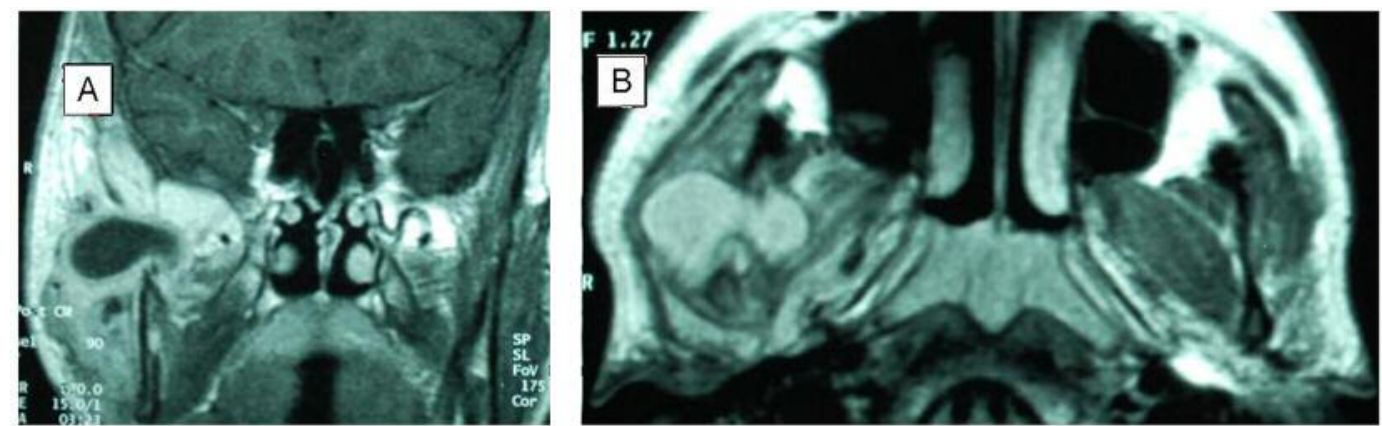

Figure 2. Magnetic resonance images of the skull. A. Coronal view of the right parotid region. A fluid-filled cavity lies inside the gland and also fills the area where the mandibular condyle cannot be visualized. B. Representation of the cyst-like cavity in axial view.
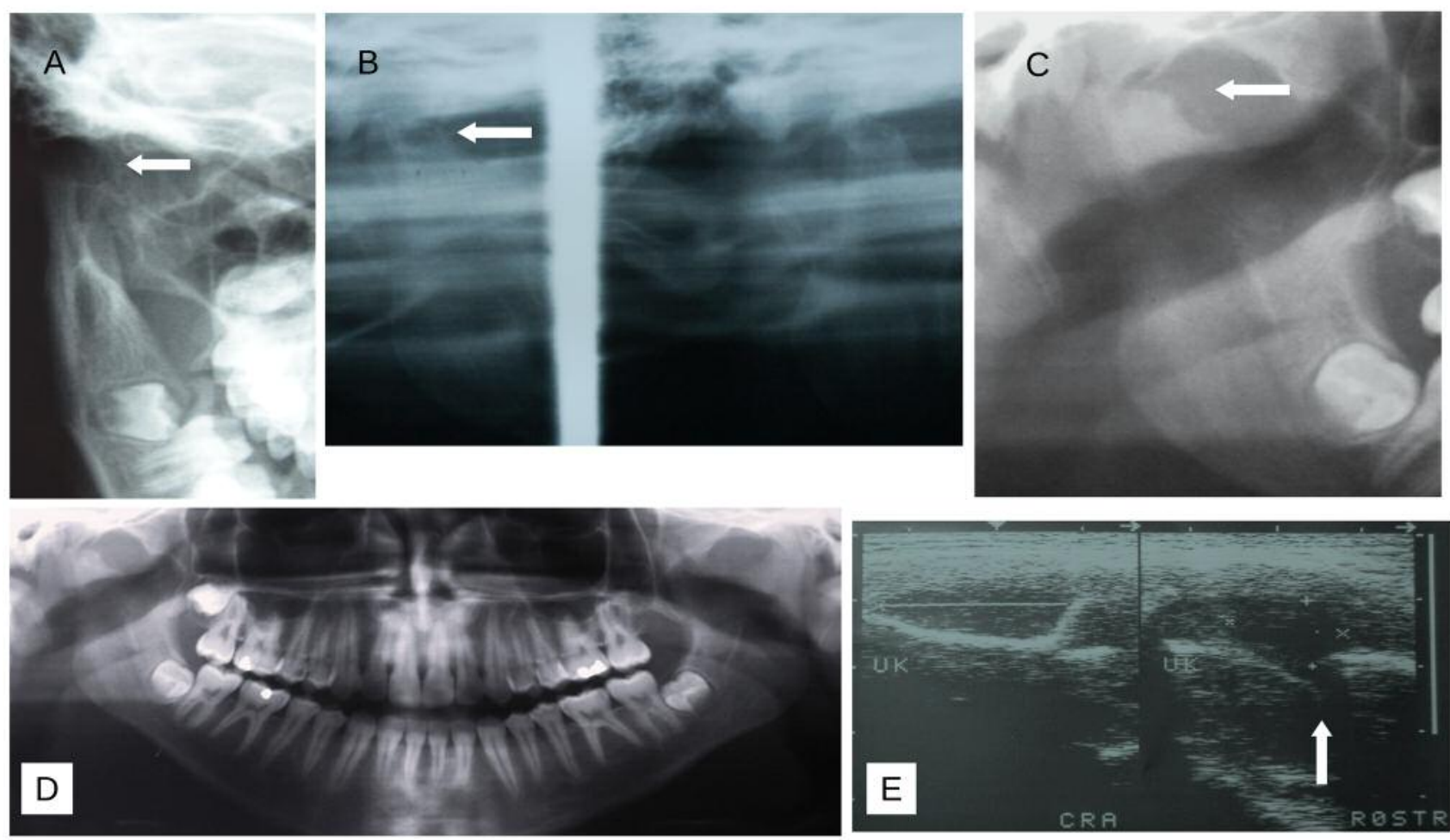

Figure 3. Radiographic and ultrasound imaging of the lower jaw. A. Posterior-anterior view of right mandible displays a dissolved mandibular capitulum (Arrow, cropped image). B. Functional representation of the right mandibular joint region with closed (Left) and open (Right) mouth (Cropped image). When the mouth is closed, a shortened articulating process is shown, the cranial boundary of which has developed a cup-like indentation. When the mouth opens, the condyle moves in front of the articular eminence. $C$ and D: The panoramic view of the jaw shows the shortened articular process in detail (Arrow in C) and overview (D). Both images show the superposition of the glenoid fossa by the skull base. E. Ultrasound imaging of the right ramus region. The accumulation of fluid lateral to the ramus is shown on the left. On the right-hand illustration, the enlarged joint gap can be seen (Arrow), which occurs between the complete ultrasound remissions of the ramus (Left) and the temporal bone (Right) (UK: mandible; CRA: cranial; RO: rostral).

the retromandibular vein was slightly displaced. In close proximity to the main lesion some small fluid accumulations were depicted. In the region of the glenoid fossa there was no condyle depicted on MRI. The tentative radiological diagnosis was traumatic osteolysis of the right articular process.
On admission, the patient was in good general condition. The patient stated that the bulging skin caused a feeling of tension. However, he reported no pain in the region. The integument appeared to be unaffected and the facial nerve function showed symmetrical innervation of the mimic 

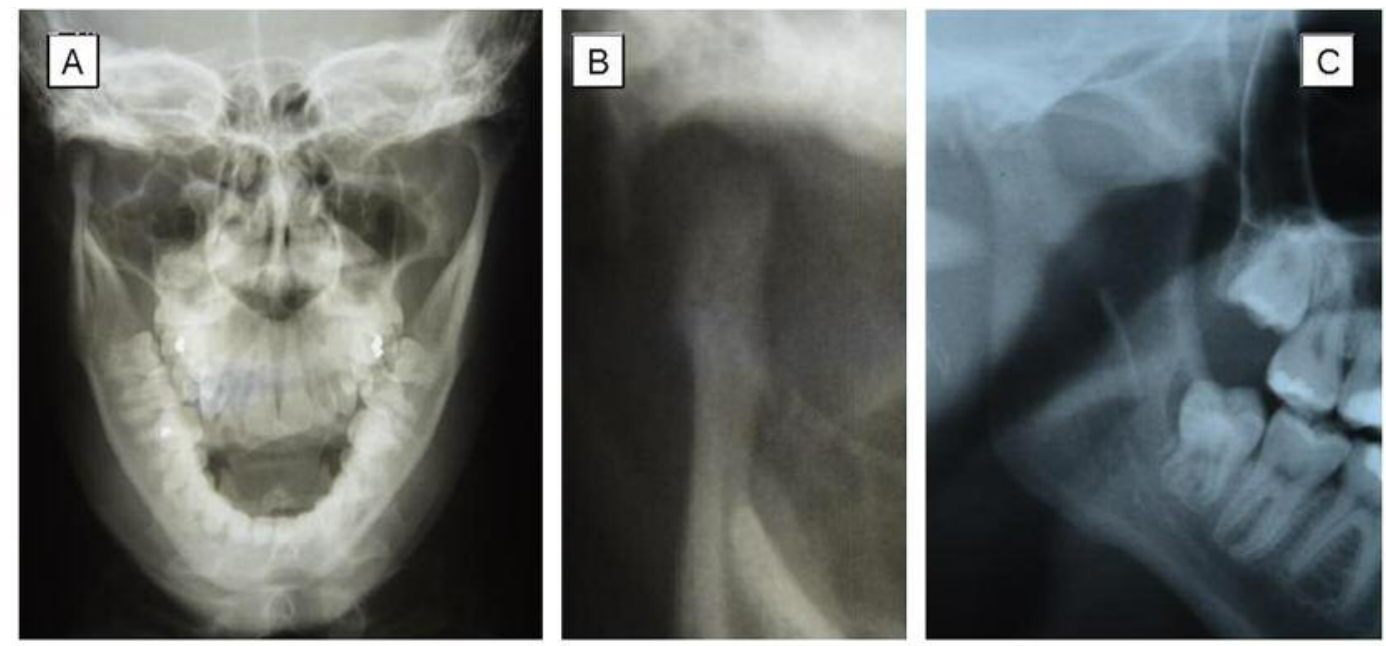

Figure 4. Radiographic representation of the right temporo-mandibular region three years after trauma. A. The cranial X-ray in posterior-anterior (p.-a.) projection with mouth opened to the maximum $(5,6)$ shows a new articular process, that is significantly smaller in height and transverse diameter than the intact articular process of the left side joint. B, Detail of A: The bony regeneration did not lead to the formation of a condylar head. The detail of the panoramic view radiography taken at the same time as p.-a. radiograph shows the superposition of the glenoid fossa and the articulating part of the mandible. The extent of bone regeneration cannot be assessed in the lateral projection.

muscles. Mouth opening was restricted to about $20 \mathrm{~mm}$ interincisional distance. The X-ray examinations of the jaws showed that the cranial parts of the articular process on the right side had dissolved (Figure 3A-D). B-scan ultrasound images revealed an inhomogeneous, hypo-echoic space occupying lesion lateral to the complete distal remittance of ultrasound conduction originating from the subcondylar ramus surface (Figure 3E). Interestingly, the sharp line of bone surface ultrasound signal suddenly stopped caudal to the echo obtained from the temporal bone, leaving a gap of ultrasound transmission to more medial parts of the skull base. This signal is typical for missing condyle in the glenoid fossa (22).

Later, the original radiographs were received and reevaluated. The functional radiograph of the right TMJ region had been carried out by plain radiography using Schüller projection of the lateral skull base. On the radiograph the condyle was somewhat displaced to the caudal-anterior direction (Figure 1). When the rows of teeth are closed, the joint gap is slightly widened and the condyle is slightly anterior and positioned on the articular eminence. This position may indicate haemorrhage to the joint region (8). As a result of superposition of different bones in the radiograph, a fracture at the base of the condylar process is possible to be identified, but cannot be clearly diagnosed in retrospect. The radiotranslucency of the dorsal part of the capitulum can be an indication of initial osteolysis (Figure 1).

Therapy and follow-up. Under local anesthesia and sterile conditions the preauricular tumour was punctured with a canula and drained with a syringe. About $10 \mathrm{ml}$ of yellowish smeary fluid was aspired. The secretion of the cavity was somewhat cloudy, but not purulent. The wound was dressed and slightly compressed by a bandage. Healing was uneventful, but as swelling recurred after a few days, the lesion was again punctured. About $1 \mathrm{ml}$ of fluid was drained. Microscopic analysis of the liquids revealed massive granulocytes but no osseous particles. Microbiological analysis of the smear of the first drainage revealed cell residues, some epithelia, moderate number of leukocytes and gram-positive rods. The second drainage revealed sparse leukocytes and cell residues but was devoid from bacteria. The swelling disappeared again and never returned. Radiological follow-up controls up to three years revealed a rounding of the concave neo-articular process (Figure 4). The mouth opening was not restricted but the patient noticed a slight deviation of the mandible during the process of mouth opening to the side of the shortened bone.

\section{Discussion}

This report demonstrates the need to consider mandibular condyle trauma in the differential diagnosis of a pre-auricular swelling in patients with considerable time interval from a facial trauma. Diagnosis was delayed due to insufficient radiological diagnosis following trauma and late medical consideration of a symptomatic patient. These shortcomings led to finally discuss a neoplasm of the temporo-mandibular region as the cause of bone destruction and cyst-like tumour of parotid region.

Monitoring the patient's course does not allow to conclude for certainty that the trauma to the skull had led to a fracture 
of the mandibular condyle. Alternatively, the trauma may have resulted in the tearing of vessels that supply the jaw joint (21). In the present case, the post-traumatic X-ray image only insufficiently depicts the potential fracture region. Regardless of these limitations in skeletal diagnostics, this unusual course shows that in an untreated patient with mandibular trauma, an insufficiently vascularized condyle can be completely resolved within a few weeks. The detection of bacteria in the drained seroma is not due to an external injury to the affected region. The number of bacteria was moderate and probably a late colonization of the destroyed bone. Infections of mandibular fractures are rare in children (23). The course of the disease in the adolescent shows the problem of establishing and proving principles of care in traumatology of this bone region. In fact, it remains questionable whether a surgical intervention based on expanded diagnostics could have prevented bone necrosis in this case.

\section{Diagnosis of mandibular condyle trauma}

Plain radiography. Diagnosis of condylar trauma must first rule out or prove the fracture of the bone (1). Radiographic diagnosis with conventional $\mathrm{X}$-ray requires at least images of the region of interest in two plains perpendicular to each other (3). Conventional projections, such as posterioranterior skull views $(5,6)$ and lateral projections of the mandible (24) allow visualization of fracture lines in the region of interest in the vast majority of cases (25). Even the estimation of ligament lesions and disc displacement is possible in cases with condylar process displacement (3) However, improper radiological projection can severely hamper the identification of fracture lines. Indeed, the representation of the capitulum fractures in computer tomography is superior to that in plain radiography (25). Furthermore, the limited but visible mobility of the condyle on a functional radiograph (Figure 1) can be taken as the result of continuous bone movement, misinterpreted as an indicator of intact bone and justify the decision of not taking any further diagnostic measures.

Panoramic view (PV) radiography of the jaw, which is currently frequently used instead of lateral or anteriorposterior plain skull projections, allows a clear representation of the lower jaw including the joint region, but only on one projection. PV requires the patient to be precisely positioned in the diagnostic device (26). However, superposition of the capitulum with the glenoid fossa is also possible in this projection despite correct placement of the patient (Figure $3 \mathrm{C}$ and $\mathrm{D}, 4 \mathrm{C})$. Furthermore, the lateral projection in PV does not ensure display of infractures. Indeed, the diagnostic accuracy of articular fracture identification is moderate with $\mathrm{PV}$, especially with diacapitular fractures $(27,28)$.

Computed tomography. Currently, several tomographic radiological devices allow the imaging of bone in several plains and circumvent the problems arising from inadequate projections of the skull base on plain radiographs $(9,29)$. However, thin sections of the examination region must be made with tomography, because otherwise some fractures will not be displayed (30). Indeed, lack of fracture displacement is the single most important factor in missed fractures with all X-ray modalities (9).

Ultrasound imaging. B-scan ultrasound examination of the condylar process region so far has not been established as an alternative to $\mathrm{X}$-ray diagnostics because non-displaced fractures can escape the display at the clinically applied emission frequencies (22).

MRI. MRI has wide range of applications in assessing derangement of the joint $(31,32)$. MRI has been used in the surgical diagnosis of the mandibular condyle primarily to assess changes in the capsule and disc after ramus osteotomies (33). In the diagnosis of condylar trauma, MRI is also mainly used to identify damage to the joint capsule and the disc $(18,34-36)$. MRI demonstrates haemarthros in $57.9 \%$ (37) to $100 \%$ of condylar trauma cases (38). MRI is not a suitable diagnostic method to identify non-displaced fractures (34). On the other hand, MRI has shown that the disc usually remains in its anatomical position even if the condylar head is dislocated (39). These findings suggest that if the fracture is dislocated, the condyle is fed via the lateral pterygoid muscle attached on the joint.

None of the methods mentioned is able to reliably assess intraosseous perfusion disorders.

Angiography. Angiographies of the mandibular joint region after skeletal trauma are mainly used to identify posttraumatic aneurysms (40-43) and so far, have not been used to control perfusion of mandibular fragments or bone regions compromised by compression.

Condylar fracture in children. Among the fractures of the lower jaw in childhood, the fracture of the articular process occupies a special position because this area is particularly often damaged (44). The causes change with the child's development. According to many studies, it is mainly falls that cause condylar fractures in early childhood. In children over the age of 10 to around 16 years, it is particularly boys who suffer this fracture in sports accidents, which occur unusually often when playing football (45). The age and circumstances of the accident victim thus correspond to epidemiological data on this type of fracture in childhood and adolescence.

Treatment concepts of condylar trauma. Published treatment strategies for condylar trauma are largely limited to fractures $(16,17,29)$ and rarely deal with the diagnosis and treatment 

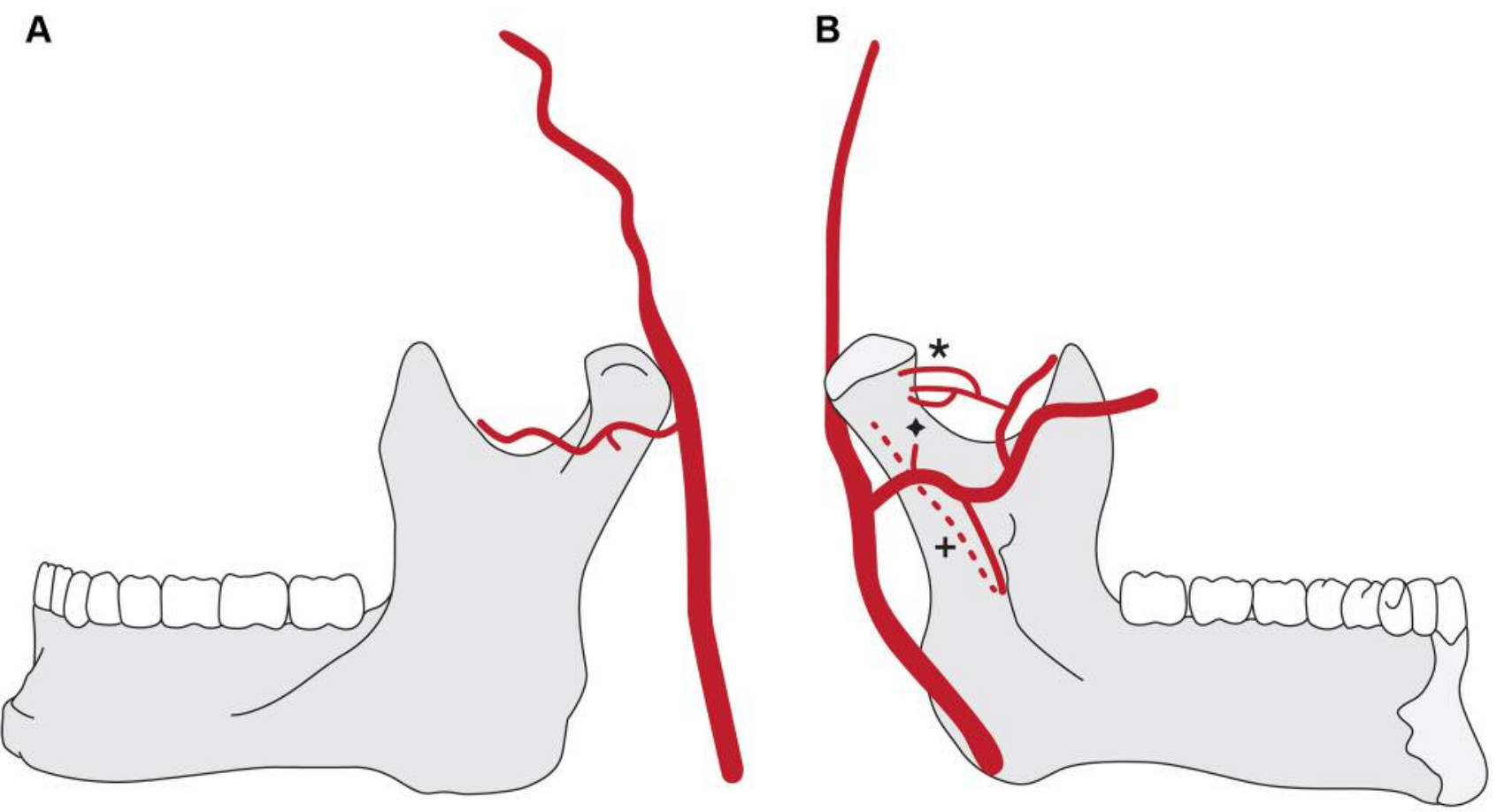

Figure 5. Schematic representation of endosteal vascular supply to mandibular ramus and condyle according to Olivetto et al. (62). Figures are slightly modified. A. The lateral aspect to the mandible is shown. The transverse facial artery is providing a direct nutrient branch reaching an accessory foramen on the lateral condylar aspect. According to these authors, this finding can be expected in about 8\% of cases. B. The oral aspect of the mandible is shown. The maxillary artery provides a direct nutrient branch to the condyle by an accessory foramen (Lower asterix). This finding can be expected in about $6 \%$ of cases. A bunch of vessels enters the condyle from anterior through a foramen of the fovea. These terminal vessels come from the maxillary artery after dividing into branches to the lateral pterygoid muscle. This vascular supply to the condyle is extremely constant and can be expected in about $91 \%$ of cases (Upper asterix). Only in very rare cases an artery of the ramus running intramedullary in cranial direction along the inferior alveolar artery reaches the condyle (Cross sign). For further details on condylar vascular anatomy, see the publication of Olivetto et al. (62).

of trauma cases, which obviously are limited to the capsule apparatus and disc $(35,37)$. Besides fracture diagnosis $(46)$, damage to the disc and ankylosis are in the foreground when analyzing post-traumatic disorders in the TMJ region on radiographic images (47). MRI of the condyle region is recommended as diagnostic procedure in suspected condylar damage (37). However, no therapeutic standards based on these imaging techniques are generally recognized in the case for TMJ trauma without apparent fracture [e.g. (im)mobilisation, arthroscopy].

However, there is no unanimous consensus regarding the treatment of condylar fractures either $(12,13,14)$. Initially, immobilisation was claimed indispensable to provide fracture healing, remodelling of the bone and long-term relief of pain in patients with condylar fracture (3). This therapeutic maxim is currently maintained by some authors for non-displaced, non-dislocated mandibular condyle fractures (12), particularly in children (48). On the other hand, there are also long-standing indications that nondislocated condylar fractures do not need immobilization (7).
This view is confirmed by some current researchers (11).

Until recently, it was proposed that children with mandibular condyle fractures should be treated conservatively, with or without maxillo-mandibular fixation (MMF) $(17,20$, 48, 49). Early mobilization after fracture treatment was proposed as the key element in treating condylar fractures in order to prevent permanent movement restrictions of the joint (49). ORIF of articular process fractures allows early functional loading of the bone and thus appears to circumvent the treatment consequences of intermediate-term TMJ immobilization (17). Convincing treatment results using ORIF in the treatment of mandibular condyle fractures have led to more surgeons and study groups advocating in favour of this therapeutic concept (10). Conservative treatments for these fractures are still approved by some surgeons (50). However, damage to the soft tissues (parotid, facial nerve) must be taken into account with ORIF when using an extra-oral approach to the joint region $(12,15,51)$. Furthermore, osteosynthesis of small fragments can be associated with severe complications such as pulling out of screws and broken plates (12). Necrosis 

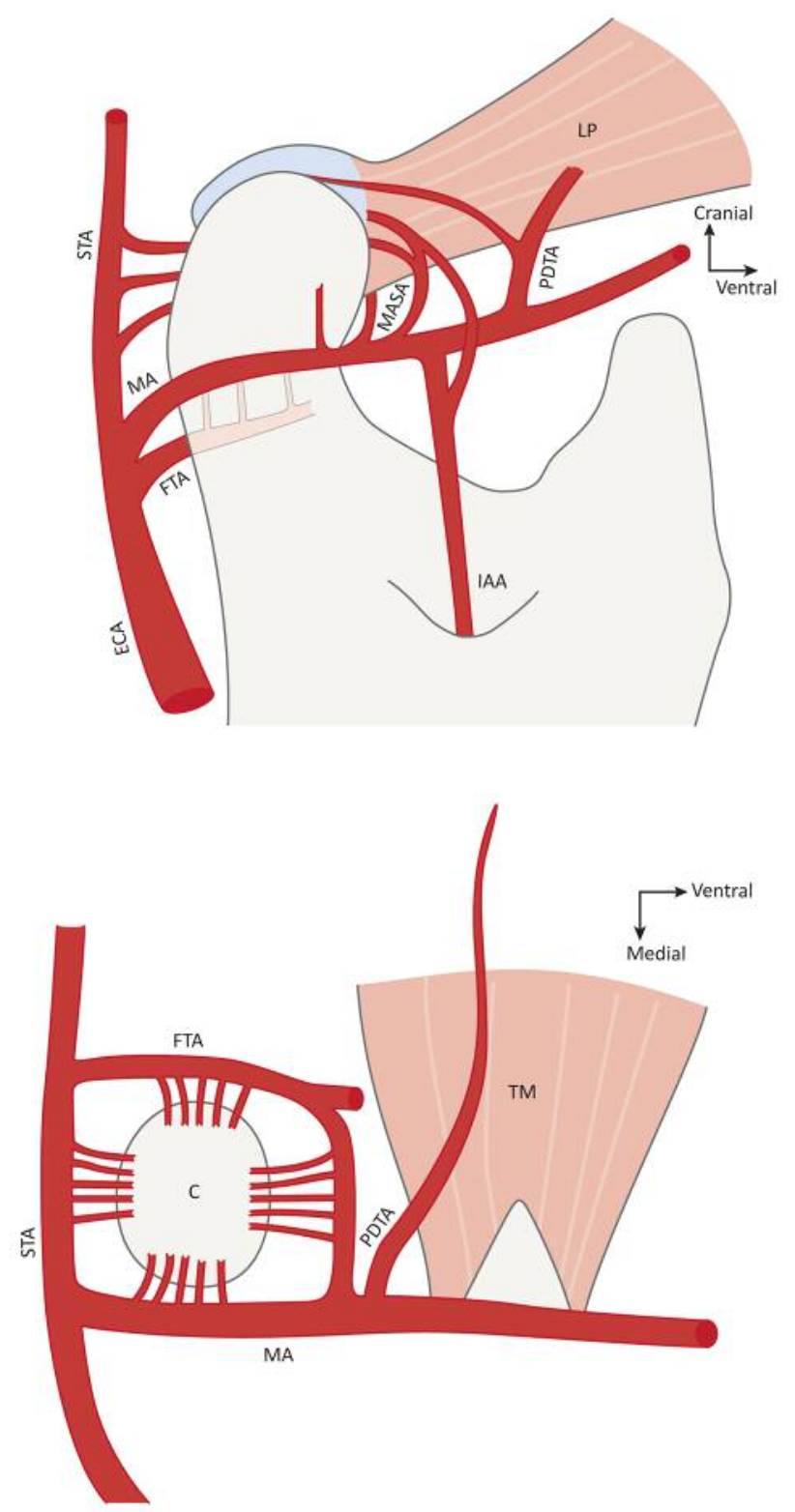

Figure 6. Schematic representation of vascular supply to mandibular condyle according to Toure (61). The figures are slightly modified. Top: Medial view of condylar region illustrating the arterial circle surrounding the articular process. Bottom: Cranial aspect of arterial supply to the condyle (STA: superficial temporal artery; LP: lateral pterygoid muscle; MA: maxillary artery; MASA: masseteric artery; PDTA: posterior deep temporal artery; FTA: facial transverse artery; ECA: external carotid artery; IAA: inferior alveolar artery; TM: temporal muscle; $C$ : condyle). For further details on condylar vascular anatomy, see the publication of Toure (61).

of the proximal fragment is still a risk of $\operatorname{ORIF}(12,51,52)$. In addition, the limitation of inclusion the age of patients to individuals over the age of 18 years in comparative studies on the effectiveness of ORIF $v s$. conservative therapy of condylar fractures shows that treatment strategies in children and adolescents are yet not clearly defined (13). However, some authors use ORIF of the condylar fractures indiscriminately for patients of all ages as therapy of choice and refer to high success rates (15). Radiological signs of resorption were observed in patients with detachment of the lateral pterygoid muscle from the proximal fragment (53) and the number of patients experiencing condylar resorption following open reduction can be as high as 100\% (11). However, other authors point out that conservative therapy with MMF produces very good treatment results in children and adolescents $(50,54)$.

The main difference in the treatment result of ORIF $v s$. conservative treatment was the deviation of the mandible to the affected side when opening the mouth in conservatively treated patients with displaced proximal fragment, loss of vertical dimension and reduced bone regeneration capacity in adults $(13,14)$. Marked remodelling was evident on computed tomograms but no complaints of temporomandibular joint function (55).

The amount of restitution of condylar height after loss or displacement of the articulating region depends on age and appears to be best in children. Holtgrave et al. (56) studied 18 children with unilateral or bilateral fractures of the condyle who were treated with conservative measures only. The clinical and radiological results showed complete restitution mainly in children aged less than 10 years whereby the true repositioning of the dislocated condylar process is of no importance. Neither ankylosis, pseudoarthrosis, neo-arthrosis nor microgenia were found in any of the tested children. The authors recommended the wire-and-acrylic splint according to Schuchardt (57) as especially appropriate for the conservative treatment (MMF) (56). The findings were confirmed by Gundlach et al. (58) and further emphasizing that the capacity to restore an articular process - though limited in every case - strongly decreases after the age of thirteen years.

Vascular supply to mandibular condyle. The mandibular condyle is surrounded by a network of circularly arranged arteries that extent small branches to the periosteum of the bone (21, 59-63) (Figures 5 and 6). Numerous foramina of the articular process testify to the dense vascular supply provided by several main arteries (61). Constantly developed vessels with branches to the condyle are the superficial temporal artery, the posterior deep temporal artery and branches arising from the maxillary artery running over the lateral pterygoid muscle to the condyle and disc (61). Other arterial branches cannot always be detected in a specimen: deep auricular artery, anterior tympanic artery, middle meningeal artery, transverse facial artery, masseteric artery and inferior alveolar artery (61). However, the lack of one or the other artery does not result in interruption of the anatomical circle of the pericondylar region. Some 
intraosseous branches of the inferior alveolar artery run in the mandibular ramus and reach the condyle. In several cases, this artery is a collateral of the masseteric artery. However, the formation of inferior alveolar artery branches to the condyle is inconsistent and often rudimentary (61). Recent studies have shown that the maxillary artery delivers both endosteal and periosteal blood to the mandibular condyle (62). These anatomical findings are interpreted as the basis for maintaining the capitulum's integrity in the event of a dislocated fracture: there exists an extensive autonomy of the arterial vascular supply of the condyle from the vascular supply of the rest of the mandible (62) and the vessels of the lateral pterygoid muscle provide sufficient vascularization of the isolated capitulum (61). The anatomical studies identify the basis of why fractures of the condyle are rarely associated with a dissolution of the bone and post-traumatic ankylosis of the joint is a much more common event to diagnose than a vanishing condyle (64). Considering the arterial vascular network of the joint region, it is difficult to explain capitulum necrosis if there is no abduction of the condylar head and detachment of the pterygoid muscle from the bone fragment.

Avascular necrosis of mandibular condyle. Avascular necrosis of the TMJ has primarily been discussed in connection with incomplete regeneration of the joint-forming segment after trauma and osteotomies of the mandibular ramus $(46,65)$. The functioning of the Starling resistor has been proposed for assessing the vascular supply of the bone and has been adapted as a pathophysiological model for understanding osteonecrosis of the mandibular condyle (66). The Starling resistor consists of a rigid body that is sharply delineated from the environment and is traversed by one or more tubes. Accordingly, the flow rate through the tubes is determined by the pressure outside the compartment in relation to the pressure inside the compartment. When this principle is applied to a bone or functionally separated part of a bone, the intramedullary space is the "tubes" through which blood flows according to current pressure. Every increase in pressure inside the compartment (and outside the "tubes") thus leads to a decrease in the intramedullary blood flow. In a corresponding way, any increase in extracompartmental pressure will reduce venous outflow $(66,67)$. In the event of severe joint contusion, it is therefore plausible that, despite the extensive arterial blood supply to the condyle, acute bleeding into the area surrounding the bone restricts the venous drainage of the injured bone in such a way that perfusion stops and the entire part of bone becomes necrotic. This pathogenesis of capitulum necrosis is apparently very rare after a TMJ trauma. The TMJ region is usually restored within a few weeks after a haemorrhage (8). Alternatively, arteries can tear in TMJ contusions. Anatomical examinations have repeatedly shown that even in the case of a complete tearing of the capitulum from the neck of the condyle and further dislocation of the head, there is a dense, circular anastomosing vascular network that keeps the bone vital, in particular through the blood supply to the fragment via the lateral pterygoid muscle (see above). In the presented case, the apparently non-displaced, compressed compartment may have been the prerequisite for increasing the extra-compartmental pressure, which, with sufficient arterial perfusion, did not allow adequate drainage. However, bone healing after a phase of immobilization is particularly beneficial for non-displaced, non-dislocated fractures. In this case, the constant influence of the chewing muscles on the perfusion of the nonimmobilized contusion or fracture cannot be calculated. There are authors who use a conservative treatment protocol for pediatric condylar fractures and document successful fracture healing in the majority of cases without intermaxillary fixation (20). At the time of the first radiological examination, no abduction of the proximal fragment, especially the condylar head, was evident on the radiograph of the presented patient. Abduction of condyle is considered to be an essential prerequisite for condylar absorption in intracapsular fractures in children (68). Absorption of the condyle was a postoperative event that was detected in 35 of 140 condylar process fractures. However, this bone loss required a considerable amount of time (about half a year with a wide spread of values) (68).

\section{Conclusion}

The course of diagnosis and therapy of an adolescent with trauma to the mandibular condyle shows the limits of current diagnostic and treatment concepts for this type of injury. The standards of radiological fracture diagnostics should be followed in each individual case. Radiological evidence of adequate mobility of the joint when the mouth is opening is no guarantee of an intact capitulum. Non-displaced fractures and vascular damage to the joint region can escape imaging.

\section{Conflicts of Interest}

The Authors have no conflicts of interest with regard to the work presented.

\section{Authors' Contributions}

REF treated the patient, researched the literature, and wrote the article. FKK checked the scientific literature and wrote the article. All Authors gave final approval for publication.

\section{Acknowledgements}

This research did not receive any specific grant from funding agencies in the public, commercial, or not-for-profit sectors. 


\section{References}

1 Vorrasi JS, Coletti DP and Caccamese JF: Diagnosis and Management of Mandible Fractures. In: Oral and Maxillofacial Surgery. Fonseca R (ed.). Elsevier, St. Louis (Miss.), pp. 146$173,2018$.

2 Larheim A and Westesson PLA: Maxillofacial Imaging, Chapter 8. Facial Traumas and Fractures. Springer, Cham, pp. 287-297, 2018. DOI: 10.1007/978-3-319-53319-3_8

3 Spiessl B and Schroll K: Spezielle Frakturen- und Luxationslehre. Thieme, Stuttgart, pp. 42-43, pp. 136-152, 1972.

4 Kurita H, Ohtsuka A, Kobayashi H and Kurashina K: Resorption of the lateral pole of the mandibular condyle in temporomandibular disc displacement. Dentomaxillofac Radiol 30: 88-91, 2001. PMID: 11313727. DOI: $10.1038 / \mathrm{sj} / \mathrm{dmfr} / 4600578$

5 Clementschitsch F: Mitteilung einer symmetrischen Aufnahme beider Kiefergelenke in postero-anteriorer Richtung. Z Stomatol 23: 877-882, 1941.

6 Clementschitsch F: Über die Röntgenuntersuchung von Gesichtsschädelverletzungen. In: Traumatologie im KieferGesichtsbereich. Reichenbach E (ed.). JA Barth, Leipzig, pp. 8087, 1969.

7 Rowe NL and Killey HC: Fractures of the Facial Skeleton. Livingstone, Edinburgh and London, pp. 137-179, 1968.

8 Müller W: Die Verletzungen des Kiefergelenks und ihre Behandlung. In: Traumatologie im Kiefer-Gesichtsbereich. Reichenbach E (ed.). JA Barth, Leipzig, pp. 283-312, 1969.

9 Markowitz B, Sinow JD, Kawamoto HK Jr, Shewmake K and Khoumehr F: Prospective comparison of axial computed tomography and standard and panoramic radiographs in the diagnosis of mandibular fractures. Ann Plast Surg 42: 163-169, 1999. PMID: 10029481. DOI: 10.1097/00000637-19990200000010

10 Neff A: Internal fixation of the condylar head. In: Kleinheinz J and Meyer C (eds.). Fractures of the Mandibular Condyle: Basic Considerations and Treatment. International Bone Research Association, Quintessence Publ., London, pp. 239-246, 2009.

11 Iizuka T and Hallermann W: Open reduction without internal fixation. In: Fractures of the Mandibular Condyle: Basic Considerations and Treatment. Kleinheinz J and Meyer C (eds.). International Bone Research Association, Quintessence Publ., London, pp. 161-166, 2009.

12 Landes CA, Day K, Glasl B, Ludwig B, Sader R and Kovács AF: Prospective evaluation of closed treatment of nondisplaced and nondislocated mandibular condyle fractures versus open reposition and rigid fixation of displaced and dislocated fractures in children. J Oral Maxillofac Surg 66: 1184-1193, 2008. PMID: 18486783. DOI: 10.1016/j.joms.2007.06.667

13 Shiju M, Rastogi S, Gupta P, Kukreja S, Thomas R, Bhugra AK, Parvatha Reddy $M$ and Choudhury R: Fractures of the mandibular condyle - Open versus closed - A treatment dilemma. J Craniomaxillofac Surg 43: 448-451, 2015. PMID: 25726918. DOI: $10.1016 / \mathrm{j} . j \mathrm{cms} .2015 .01 .012$

14 Stypulkowski RP, Santos AG, de Paula E Silva E, da Costa Moraes CA and da Rosa ELS: Unilateral mandibular condylar process fractures: a retrospective clinical comparison of open versus closed treatment. Oral Maxillofac Surg 23: 209-214, 2019. PMID: 31069563. DOI: 10.1007/s10006-019-00760-7

15 He D, Yang C, Chen M, Jiang B and Wang B: Intracapsular condylar fracture of the mandible: Our classification and open treatment experience. J Oral Maxillofac Surg 67: 1672-1679, 2009. PMID: 19615581. DOI: 10.1016/j.joms.2009.02.012.

16 Hlawitschka M, Loukota $\mathrm{R}$ and Eckelt U: Functional and radiological results of open and closed treatment of intracapsular (diacapitular) condylar fractures of the mandible. Int J Oral Maxillofac Surg 34: 597-604, 2005. PMID: 16053886. DOI: 10.1016/j.ijom.2005.02.004

17 Boffano P, Benech R, Gallesio C, Arcuri F and Benech A: Current opinions on surgical treatment of fractures of the condylar head. Craniomaxillofac Trauma Reconstr 7: 92-100, 2014. PMID: 25050145. DOI: 10.1055/s-0034-1371772.

18 Liu M, Zhao Y, He Y, An J, Lei J and Zhang Y: Outcomes of anterior disc displacement and condylar remodelling for sagittal fracture of the mandibular condyle in children after closed treatment. Int J Oral Maxillofac Surg 49: 82-89, 2020. PMID: 31076199. DOI: 10.1016/j.ijom.2019.03.901

19 Zhu YF, Zou Y, Wang SZ, Du CX, Xu B and Zhu M: Threedimensional evaluation of condylar morphology after closed treatment of unilateral intracapsular condylar fracture in children and adolescents. J Craniomaxillofac Surg pii: S10105182(20)30023-8, 2020. PMID: 32070660. DOI: 10.1016/j.jcms. 2020.01 .015

20 McGoldrick DM, Parmar P, Williams R, Monaghan A and McMillan K: Management of pediatric condyle fractures. J Craniofac Surg 30: 2045-2047, 2019. PMID: 31369504. DOI: 10.1097/SCS.0000000000005787

21 Voy ED and Fuchs M: Anatomische Untersuchungen zur Blutgefäßstruktur im Bereich des Kiefergelenks. In: Schuchardt K (ed.). Fortschritte der Kiefer-Gesichts-Chirurgie, Vol. 25, Thieme, Stuttgart, pp. 2-5, 1980.

22 Friedrich RE, Plambeck K, Bartel-Friedrich S, Giese M and Schmelzle R: Limitations of B-scan ultrasound for diagnosing fractures of the mandibular condyle and ramus. Clin Oral Investig 5: 11-16, 2001. PMID: 11355092. DOI: 10.1007/p100010679

23 Oji C: Fractures of the facial skeleton in children: a survey of patients under the age of 11 years. J Craniomaxillofac Surg 26: 322-325, 1998. PMID: 9819684. DOI: 10.1016/s10105182(98)80062-0

24 Youssefzadeh S: Postoperative imaging of the temporomandibular joint. Top Magn Reson Imaging 10: 193-202, 1999. PMID: 10616811. DOI: 10.1097/00002142-199908000-00001

25 Schimming R, Eckelt U and Kittner T: The value of coronal computer tomograms in fractures of the mandibular condylar process. Oral Surg Oral Med Oral Pathol Oral Radiol Endod 87: 632-639, 1999. PMID: 10348526. DOI: 10.1016/s10792104(99)70147-2

26 Wikner J, Friedrich RE, Rashad A, Schulze D, Hanken H, Heiland M, Gröbe A and Riecke B: Obstacles in spatial evaluation of CBCT-reformatted panoramic imaging. Dentomaxillofac Radiol 45: 20150436, 2016. PMID: 26959644. DOI: $10.1259 / \mathrm{dmfr} .20150436$

27 Chacon GE, Dawson KH, Myall R and Beirne OR: A comparative study of 2 imaging techniques for the diagnosis of condylar fractures in children. J Oral Maxillofac Surg 61: 668672, 2003. PMID: 12796873. DOI: 10.1053/joms.2003.50134

28 Cho BH: Diagnostic performance of dental students in identifying mandibular condyle fractures by panoramic radiography and the usefulness of reference images. Imaging Sci Dent 41: 53-57, 2011. PMID: 21977475. DOI: 10.5624/isd. 2011.41.2.53 
29 Feifel H, Albert-Deumlich J and Riediger D: Long-term followup of subcondylar fractures in children by electronic computerassisted recording of condylar movements. Int J Oral Maxillofac Surg 21: 70-76, 1992. PMID: 1602162. DOI: 10.1016/s09015027(05)80534-x

30 Sirin Y, Guven K, Horasan S, Sencan S, Bakir B, Barut O, Tanyel C, Aral A and Firat D: The influence of secondary reconstruction slice thickness on NewTom 3G cone beam computed tomography-based radiological interpretation of sheep mandibular condyle fractures. Oral Surg Oral Med Oral Pathol Oral Radiol Endod 110: 638-647, 2010. PMID: 20889356. DOI: 10.1016/j.tripleo.2010.05.053

31 Schellhas KP, Wilkes CH, Fritts HM, Omlie MR, Heithoff KB and Jahn JA: Temporomandibular joint: MR imaging of internal derangements and postoperative changes. AJR Am J Roentgenol 150: 381-389, 1988. PMID: 3257330. DOI: 10.2214/ajr.150.2.381

32 Katzberg RW and Tallents RH: Normal and abnormal temporomandibular joint disc and posterior attachment as depicted by magnetic resonance imaging in symptomatic and asymptomatic subjects. J Oral Maxillofac Surg 63: 1155-1161, 2005. PMID: 16094584. DOI: 10.1016/j.joms.2005.04.012

33 Westesson PL, Dahlberg G, Hansson LG, Eriksson L and Ketonen L: Osseous and muscular changes after vertical ramus osteotomy. A magnetic resonance imaging study. Oral Surg Oral Med Oral Pathol 72: 139-145, 1991. PMID: 1923390. DOI: 10.1016/0030-4220(91)90152-3

34 Sullivan SM, Banghart PR and Anderson Q: Magnetic resonance imaging assessment of acute soft tissue injuries to the temporomandibular joint. J Oral Maxillofac Surg 53: 763-766, 1995. PMID: 7595789. DOI: 10.1016/0278-2391(95)90326-7

35 Dwivedi AN, Tripathi R, Gupta PK, Tripathi S and Garg S: Magnetic resonance imaging evaluation of temporomandibular joint and associated soft tissue changes following acute condylar injury. J Oral Maxillofac Surg 70: 2829-2834, 2012. PMID: 23141983. DOI: $10.1016 /$ j.joms.2012.08.026

36 Naeem A, Gemal $H$ and Reed D: Imaging in traumatic mandibular fractures. Quant Imaging Med Surg 7: 469-479, 2017. PMID: 28932703. DOI: 10.21037/qims.2017.08.06

37 Gerhard S, Ennemoser T, Rudisch A and Emshoff R: Condylar injury: magnetic resonance imaging findings of temporomandibular joint soft-tissue changes. Int J Oral Maxillofac Surg 36: 214-218, 2007. PMID: 17223310. DOI: 10.1016/j.ijom.2006.09.013

38 Weinberg FM, Speksnijder CM, Forouzanfar T and Rosenberg AJWP: Articular soft tissue injuries associated with mandibular condyle fractures and the effects on oral function. Int $\mathrm{J}$ Oral Maxillofac Surg 48: 746-758, 2019. PMID: 30773333. DOI: 10.1016/j.ijom.2019.01.025

39 Takaku S, Yoshida M, Sano T and Toyoda T: Magnetic resonance images in patients with acute traumatic injury of the temporomandibular joint: a preliminary report. J Craniomaxillofac Surg 24: 173-177, 1996. PMID: 8842909. DOI: 10.1016/s10105182(96)80052-7

40 Lai JP, Hsieh $\mathrm{CH}$, Chen YR and Liang CC: Unusual late vascular complications of sagittal split osteotomy of the mandibular ramus. J Craniofac Surg 16: 664-668, 2005. PMID: 16077313. DOI: $10.1097 / 01 . s c s .0000168774 .09475 .35$

$41 \mathrm{Li} \mathrm{W}$, Long X and Deng M: Superficial temporal artery pseudoaneurysm: report of a rare case secondary to mandibular condylar fracture. J Craniofac Surg 24: e360-e361, 2013. PMID: 23851869. DOI: 10.1097/SCS.0b013e3182902f15.
42 Susarla SM, Peacock ZS, Williams WB, Rabinov JD, Keith DA and Kaban LB: Role of computed tomographic angiography in treatment of patients with temporomandibular joint ankylosis. J Oral Maxillofac Surg 72: 267-276, 2014. PMID: 24268963. DOI: $10.1016 /$ j.joms.2013.09.024.

43 Ribeiro Ribeiro AL, Brasil da Silva W, Alves-Junior Sde M and de Jesus Viana Pinheiro J: Giant life-threatening external carotid artery pseudoaneurysm caused by a mandibular condylar fracture. Oral Surg Oral Med Oral Pathol Oral Radiol 119: e95-e100, 2015. PMID: 25442245. DOI: 10.1016/j.oooo.2014.08.017. E

44 Rostyslav Y, Yakovenko L and Irina P: Fractures of the lower jaw in children (causes, types, diagnosis and treatment). Retrospective 5 year analysis. J Oral Biol Craniofac Res 10: 15, 2020. PMID: 32025479. DOI: 10.1016/j.jobcr.2020.01.004

45 Smith DM, Bykowski MR, Cray JJ, Naran S, Rottgers SA, Shakir S, Vecchione L, Schuster L and Losee JE: 215 mandible fractures in 120 children: demographics, treatment, outcomes, and early growth data. Plast Reconstr Surg 131: 1348-1358, 2013. PMID: 23714795. DOI: 10.1097/PRS.0b013e31828bd503.

46 Giannakopoulos HE, Quinn PD, Granquist E and Chou JC: Posttraumatic temporomandibular joint disorders. Craniomaxillofac Trauma Reconstr 2: 91-101, 2009. PMID: 22110802. DOI: $10.1055 / \mathrm{s}-0029-1215872$

47 Norman JE: Post-traumatic disorders of the jaw joint. Ann R Coll Surg Engl 64: 29-36, 1982. PMID: 7055365.

48 Shi J, Chen $\mathrm{Z}$ and $\mathrm{Xu} \mathrm{B}$ : Causes and treatment of mandibular and condylar fractures in children and adolescents: a review of 104 cases. JAMA Otolaryngol Head Neck Surg 140: 203-207, 2014. PMID: 24408746. DOI: 10.1001/jamaoto.2013.6300

$49 \mathrm{Kim} \mathrm{JH}$ and Nam DH: Closed reduction of displaced or dislocated mandibular condyle fractures in children using threaded Kirschner wire and external rubber traction. Int J Oral Maxillofac Surg 44: 1255-1259, 2015. PMID: 26117724. DOI: 10.1016/j.ijom.2015.06.004

50 Naran S, Keating J, Natali M, Bykowski M, Smith D, Martin B and Losee JE: The safe and efficacious use of arch bars in patients during primary and mixed dentition: a challenge to conventional teaching. Plast Reconstr Surg 133: 364-366, 2014. PMID: 24469169. DOI: 10.1097/01.prs.0000436842.07871.b6

51 Neff A, Kolk A, Deppe H and Horch HH: Neue Aspekte zur Indikation der operativen Versorgung intraartikulärer und hoher Kiefergelenkluxationsfrakturen [New aspects for indications of surgical management of intra-articular and high temporomandibular dislocation fractures]. Mund Kiefer Gesichtschir 3: 24-29, 1999. PMID: 10077964. DOI: 10.1007/s100060050088

52 Vesnaver A: Open reduction and internal fixation of intraarticular fractures of the mandibular condyle: our first experiences. J Oral Maxillofac Surg 66: 2123-2129, 2008. PMID: 18848112. DOI: 10.1016/j.joms.2008.06.010

53 Pereira MD, Marques A, Ishizuka M, Keira SM, Brenda E and Wolosker AB: Surgical treatment of the fractured and dislocated condylar process of the mandible. J Craniomaxillofac Surg 23: 369-376, 1995. PMID: 8839331. DOI: 10.1016/s1010-5182(05) 80132-5

$54 \mathrm{Xu} \mathrm{Y,} \mathrm{Gong} \mathrm{SG,} \mathrm{Zhu} \mathrm{F,} \mathrm{Li} \mathrm{M} \mathrm{and} \mathrm{Biao} \mathrm{X:} \mathrm{Conservative}$ orthodontic fixed appliance management of pediatric mandibular bilateral condylar fracture. Am J Orthod Dentofacial Orthop 150: 181-187, 2016. PMID: 27364219. DOI: 10.1016/j.ajodo. 2016.02 .012 
55 Ghasemzadeh A, Mundinger GS, Swanson EW, Utria AF and Dorafshar AH: Treatment of pediatric condylar fractures: A 20year experience. Plast Reconstr Surg 136: 1279-1288, 2015. PMID: 26595021. DOI: 10.1097/PRS.0000000000001811

56 Holtgrave E, Rösli A and Spiessl B: Die Behandlung der Kollumfraktur im Kindesalter - Klinische und röntgenologische Ergebnisse [The treatment of collum fractures in children, clinical and radiographic results]. Dtsch Zahnarztl Z 30: 213$221,1975$.

57 Schuchardt K: Ein Vorschlag zur Verbesserung der Drahtschienenverbände. Dtsch Zahn Mund Kieferheilk 24: 3944, 1956.

58 Gundlach KK, Schwipper E and Fuhrmann A: Die Regenerationsfähigkeit des Processus condylaris mandibulae. [The regenerative capability of the condylar process of the mandible]. Dtsch Zahnärztl Z 46: 36-38, 1991. PMID: 1811967.

59 Wysocki J, Reymond J and Krasucki K: Vascularization of the mandibular condylar head with respect to intracapsular fractures of mandible. J Craniomaxillofac Surg 40: 112-115, 2012. PMID: 21470868. DOI: $10.1016 /$ j.jcms.2011.03.017

60 Cuccia AM, Caradonna C, Caradonna D, Anastasi G, Milardi D, Favaloro A, De Pietro A, Angileri TM, Caradonna L and Cutroneo G: The arterial blood supply of the temporomandibular joint: an anatomical study and clinical implications. Imaging Sci Dent 43: 37-44, 2013. PMID: 23525363. DOI: 10.5624/isd.2013.43.1.37

61 Toure G: Arterial vascularization of the mandibular condyle and fractures of the condyle. Plast Reconstr Surg 141: 718e-725e, 2018. PMID: 29697622. DOI: 10.1097/PRS.0000000000004295

62 Olivetto M, Bettoni J, Duisit J, Chenin L, Bouaoud J, Dakpé S, Devauchelle B and Lengelé B: Endosteal blood supply of the mandible: Anatomical study of nutrient vessels in the condylar neck accessory foramina. Surg Radiol Anat 42: 35-40, 2020. PMID: 31451905. DOI: 10.1007/s00276-019-02304-w
63 Castelli WA and Huelke DF: The arterial system of the head and neck of the rhesus monkey with emphasis on the external carotid system. Am J Anat 116: 149-169, 1965. PMID: 14283279. DOI: 10.1002/aja.1001160108

64 Nagori SA, Jose A, Bhutia O and Roychoudhury A: Undiagnosed mandibular condylar fractures causing temporomandibular joint ankylosis: A problem in northern India. Natl Med J India 27: 251255, 2014. PMID: 26037423.

65 Abobaker O: Avascular necrosis of the mandibular condyle: Fact or fantasy. (Letter to the editor). J Oral Maxillofac Surg 47: 1007, 1989. PMID: 2760726. DOI: 10.1016/0278-2391(89)90402-3

66 Chuong R, Piper MA and Boland TJ: Osteonecrosis of the mandibular condyle. Pathophysiology and core decompression. Oral Surg Oral Med Oral Pathol Oral Radiol Endod 79: 539-545, 1995. PMID: 7600213. DOI: 10.1016/s1079-2104(05)80091-5

67 Chuong R and Piper MA: Avascular necrosis of the mandibular condyle-pathogenesis and concepts of management. Oral Surg Oral Med Oral Pathol 75: 428-432, 1993. PMID: 8464604. DOI: 10.1016/0030-4220(93)90164-y

68 Zhou HH, Lv K, Yang RT, Li Z, Yang XW and Li ZB: Abduction of the condyle head leads to condylar resorption: A radiologic study in children with intracapsular fractures. Int $\mathbf{J}$ Pediatr Otorhinolaryngol 123: 168-174, 2019. PMID: 31112840. DOI: $10.1016 /$ j.ijporl.2019.05.013
Received March 17, 2020

Revised March 24, 2020

Accepted March 26, 2020 